\title{
The market application analysis of CAPM model in China's securities
}

\author{
Peng Zhang ${ }^{1, a}$,Xianghuan Meng ${ }^{2, b}$ \\ ${ }^{1,2}$ School of Management, Wuhan University of Science and Technology, Wuhan, P.R.China \\ azhangpeng300478@yahoo.com.cn, 'bmeng344615746@yahoo.cn
}

Key words: CAPM; Security; Risk; Investment

\begin{abstract}
CAPM is one of the most important decision-making problems for most organizations in portfolio selection problem. Usually the determination of the capital return on assets is the core issues of CAPM.The paper deeply makes the empirical analysis of CAPM model in Chinese stock market .The result could help Chinese investors understand pricing behavior and effectively guide the formulation of investment strategies in Chinese stock market.As a result, empirical research carried out many problems, especially no any effective test methods exist. From the former empirical test paper, the majority of results show that the CAPM does not apply to the current Chinese stock market. Therefore, Chinese stock market is still in development,not a mature market and far away from a standard market.
\end{abstract}

\section{Introduction}

The portfolio theory deals with the question of how to find an optimal distribution of the wealth among various assets.Markowitz(1950) measured the investment risks by the variance and proposed the mean-variance formulation which laid the foundation of the modern portfolio theory [1]. From then on , Sharp (1964), Lin Turner (1966) [2,3]put forward the famous the capital asset pricing model (CAPM). Fama and French (1992)[5] studied all sorts of CAPM to early abnormal phenomena research conducted a comprehensive, CAPM predicted relationship does not exist.However, Kothari, Shanken and Sloan (1995)[6] thought the former conclusion in different identified method is inconsistent. Ferson, Sarkissian and Simin's (FSS) (2008) conditional $\beta$ model was applied to estimate the conditional $\beta$ of CAPM for generating the positive and negative abnormal returns. Agrawal, Mohapatra (2012) [7]obtained several statistically significant results inconsistent with the hypothesis. These inconsistencies are much less pronounced during the last two decades before 1990 .

In these views, according to the reality of the China stock in 2012, This paper tests the applicability of the CAPM through an empirical research which takes the Shanghai stock exchange as an example.

\section{CAPM model}

In this paper,we consider a capital market with $\mathrm{n}$ risk assets offering random rates of returens. $R_{i}$ $(i=1,2, \ldots, n)$ stands for portfolio return rate vector; $r_{i}=E\left(R_{i}\right)$ the expected return of $R_{i}(i=1,2, \ldots, n)$; ; covariance matrix $G=\left(\sigma_{i j}\right)_{n \times n}, \sigma_{i j}=\operatorname{COV}(R i, R j),(i, j=1,2, \ldots, n)$. Due to $r_{M}=x_{m 3} r_{3}+\ldots+x_{M n} r_{n}$, hence:

$$
\begin{gathered}
\sigma_{M}^{2}=\operatorname{cov}\left(r_{M}, r_{M}\right)=\sum_{i=2}^{n} x_{i M} \times \operatorname{cov}\left(r_{i}, r_{M}\right) \\
\beta_{i}=\operatorname{cov}\left(r_{i}, r_{M}\right) / \sigma_{M}^{2}
\end{gathered}
$$

Constructing recombination $T$ by a single securities $i$ and the market portfolio $M$, where $x_{i}$ is the rate of wealth invested in $i$ th asset to the entire wealth(Not including $i$ part belong to $M$ securities); $x_{M}$ : the rate of wealth invested the entire $M$ wealth ,the Earnings expectations formula and variance formula: 


$$
\begin{gathered}
E\left(r_{t}\right)=x_{i} \times E\left(r_{i}\right)+x_{M} \times E\left(r_{M}\right) \\
\sigma_{T}^{2}=x_{i}^{2} \times \sigma_{i}^{2}+x_{M}^{2} \times \sigma_{M}^{2}+2 \times x_{i} \times x_{M} \times \sigma_{i M}
\end{gathered}
$$

The portfolio $T$ will fall in straight line which is the combination of market assets group $M$ and the stock $i$, the joint line is showed by (2.3) and (2.4), its shape depends on the correlation coefficient $\beta_{i M}$. Moreover, the tangent slope that of the $M$ point will be equal to the capital market line slope, namely:

$$
r_{e}=\left(E\left(r_{M}\right)-r_{F}\right) / \sigma_{M}
$$

Equation (2.5) is a curve which is expressed by the form of parameter equation. Through the relevant mathematical deduction, the point of tangency $\mathrm{M}$ can be calculated. Its expression formula is:

$$
\sigma_{M}\left[E\left(r_{i}\right)-E\left(r_{M}\right)\right] /\left[\sigma_{i M}-\sigma_{M}^{2}\right]
$$

Using the same conclusion, and reduction can get the following equation:

$$
E\left(r_{i}\right)-r_{F}=\beta_{i} \times\left[E\left(r_{M}-r_{F}\right)\right]
$$

The left side of the equation means risk reward, $E\left(r_{M}\right)-r_{F}$ means the whole market risk reward, $\beta_{i}$ means the securities $i$ contribution of risk for the market portfolio. From this equation, according to their risk contribution rate ,it is known that each kind of assets will have to share the risk of a portfolio .

For an arbitrary portfolio $P$, the following equation :

$$
\begin{gathered}
E\left(r_{P}\right)-r_{F}=\beta_{P}\left[E\left(r_{M}\right)-r_{F}\right] \\
\beta_{P}=\operatorname{cov}\left(r_{P}, r_{M}\right) / \sigma_{M}^{2}=x_{1} \times \beta_{1}+x_{2} \times \beta_{2}+\ldots+x_{n} \times \beta_{n}
\end{gathered}
$$

\section{Empirical research}

Let us consider the following twenty securities which choosed from Shanghai 50 stocks. The paper uses arithmetic of every stock as the rate of stock portfolio weekly return. The rate of risk free asset returns can get through the interest rates of savings deposits, treasury bill rates and bond repurchase rate. In this paper, the following formula means the rate of return: $R t=\left(P_{t}-P_{t-1}\right) / P_{t-}$ ${ }_{1}\left(P_{t}\right.$ :week closing price of period $\mathrm{t}, P_{t-1}$ : week closing price of period $\left.t\right)$ [8]. Following is the introduction of the CAPM empirical test: the $\beta$ coefficient list,

Table 1 the $\beta$ coefficient list

\begin{tabular}{cccccc}
\hline Stock code & Stock name & covariance & Market Index Variance & $\beta$ coefficient & Weekly return \\
600100 & $\mathrm{~S}_{1}$ & -0.00011 & 0.001004 & -0.11172 & 0.024067337 \\
600050 & $\mathrm{~S}_{2}$ & 0.001082 & 0.001004 & 1.077698 & 0.002255937 \\
600716 & $\mathrm{~S}_{3}$ & 0.000715 & 0.001004 & 0.712113 & 0.006190073 \\
600328 & $\mathrm{~S}_{4}$ & 0.001291 & 0.001004 & 1.285524 & 0.015625435 \\
600707 & $\mathrm{~S}_{5}$ & 0.000241 & 0.001004 & 0.239878 & -0.00136116 \\
600696 & $\mathrm{~S}_{6}$ & 0.010214 & 0.001004 & 10.1733 & 0.636040023 \\
600452 & $\mathrm{~S}_{7}$ & 0.000154 & 0.001004 & 0.153327 & 0.00938665 \\
600005 & $\mathrm{~S}_{8}$ & 0.000854 & 0.001004 & 0.850688 & 0.002934658 \\
600272 & $\mathrm{~S}_{9}$ & 0.000675 & 0.001004 & 0.672434 & 0.006677273 \\
600354 & $\mathrm{~S}_{10}$ & 0.000736 & 0.001004 & 0.732848 & 0.010802466 \\
600805 & $\mathrm{~S}_{11}$ & 0.001091 & 0.001004 & 1.086765 & 0.023133779 \\
601005 & $\mathrm{~S}_{12}$ & 0.000658 & 0.001004 & 0.655846 & 0.001436169 \\
600810 & $\mathrm{~S}_{13}$ & 0.000669 & 0.001004 & 0.666522 & 0.011574123 \\
600612 & $\mathrm{~S}_{14}$ & 0.001101 & 0.001004 & 1.096616 & 0.000678981 \\
600000 & $\mathrm{~S}_{15}$ & 0.000915 & 0.001004 & 0.911667 & 0.000328257 \\
691628 & $\mathrm{~S}_{16}$ & 0.000849 & 0.001004 & 0.84527 & -0.003152332 \\
\hline
\end{tabular}




\begin{tabular}{llllll}
\hline 601857 & $\mathrm{~S}_{17}$ & 0.000707 & 0.001004 & 0.704428 & 0.003779229 \\
600019 & $\mathrm{~S}_{18}$ & 0.000821 & 0.001004 & 0.818046 & 0.004763123 \\
600679 & $\mathrm{~S}_{19}$ & 0.000542 & 0.001004 & 0.539527 & 0.017509525 \\
600975 & $\mathrm{~S}_{20}$ & 0.000727 & 0.001004 & 0.724099 & 0.008381313 \\
\hline
\end{tabular}

Identified $\beta$ coefficient can be used to make regression test and the corresponding inspection .Half of the cross section data, the regression equation is [9]:

$$
R_{i}=\gamma_{0}+\gamma_{1} \beta_{i}+\mu_{i}
$$

Through calculating, the regression lines value of the 20 stocks return $: \gamma_{1}=0.06476$, it means that there is a good linear relationship and positive linear correlation of return rate and risk in the Shanghai stock market .

This paper adopts the Shanghai A stock index as the market portfolio .The test of relationship between return and risk be easy to generate deviation. Therefore, constructed portfolio disperse most of the non systematic risks [10].

The risk-free rate can be calculated by deposit interest rate of half time, since there be upward trend of deposit rates, some data can be calculated for the mean .Then useing the BJS method to test:

Firstly, according to the number of return , 20 stocks in accordance with the $\beta$ coefficients are divided into four groups [4], as shown in the following table:

Table 2The Sample packets

\begin{tabular}{cccc}
\hline The first group & The second group & The third group & The fourth group \\
\hline $\mathrm{S}_{1}$ & $\mathrm{~S}_{3}$ & $\mathrm{~S}_{2}$ & $\mathrm{~S}_{1}$ \\
\hline $\mathrm{S}_{5}$ & $\mathrm{~S}_{6}$ & $\mathrm{~S}_{10}$ & $\mathrm{~S}_{8}$ \\
\hline $\mathrm{S}_{7}$ & $\mathrm{~S}_{11}$ & $\mathrm{~S}_{12}$ & $\mathrm{~S}_{15}$ \\
\hline $\mathrm{S}_{9}$ & $\mathrm{~S}_{13}$ & $\mathrm{~S}_{17}$ & $\mathrm{~S}_{16}$ \\
\hline $\mathrm{S}_{19}$ & $\mathrm{~S}_{14}$ & $\mathrm{~S}_{20}$ & $\mathrm{~S}_{18}$ \\
\hline
\end{tabular}

In order to improve the validity of $\beta$ coefficient, portfolio return in the first period would be estimated to get $\beta$, which would be tested for the relation with the combination rate of return in the second period. According to the following model linear regression.

$$
R_{p j}=\gamma_{0}+\gamma_{1} \beta_{p j}
$$

$R_{p j}$ is average weekly earnings rate of portfolio $\mathrm{j} ; \beta_{p j}$ is $\beta$ coefficient of portfolio $j ; \gamma_{0}, \gamma_{1}$ : the estimated parameters.Regression results are as follows:

Table 3 The Regression results

\begin{tabular}{ccc}
\hline intercept & gradient & correlation coefficient \\
\hline 0.099987 & 0.194401 & 0.210414 \\
\hline
\end{tabular}

The regression coefficients $\gamma_{1}$ be not remarkable equal to 0 , namely returns and risks have good linear relation in Shanghai stock market. however when $\beta$ coefficient be measured by other methods, inspection conclusion may have different and even opposite.

\section{Conclusion}

Through the empirical research, the paper studied the company development ability and profit ability and got the concludsiong that returns and risks have good linear relation in Shanghai stock market. The constraints of the capital scale and professional level, and lacking rational investment philosophy leads to the low efficiency of investment. But it tells us that there should be a positive relationship between risks and benefits, actually the relationship is definitely established in a mature capital market, along with the development of China's securities market, this relationship will be more and more obvious .

\section{Acknowledgements}

This work was supported by NSFC, No. 71271161; SSFMEC, No.09YJC630182.

\section{References}


[1] Markowitz, H.: Portfolio selection, The Journal of Finance [ J ]. 1952, 7 (1): 77 - 91.

[2] Sharpe ,W. F.: New Evidence on the Capital Asset Pricing Model: Discussion, The Journal of Finance .1978,33(3):917-920

[3] Lintner, J.: The Valuation of Risk Assets and the Selection of Risky Investments in Stock Portfolios and Capital Budgets, The Review of Economics and Statistics.1965,47(1):13-50

[4] Lin,D. Asset pricing theory and the empirical research in Chinese stock market[D]. Tianjin university master degree theses.2005.5-40

[5] Fama , E. F .,French ,K.R.: The Cross-Section of Expected Stock Returns, The Journal of Finance.1992,47(2):427-465

[6] Kothari ,S . P., Shanken,J.,Sloan,R.G.: Another Look at the Cross-Section of Expected Stock Returns, Journal of Finance.1995,50(1):185-224

[7] Agrawal,M., Mohapatra,D., Empirical evidence against CAPM: Relating alphas and returns to betas[J], IEEE Journal on Selected Topics in Signal Processing. 2012(4): 298-310

[8] Zhu,S.Q., The empirical research of CAPM in China's capital market [C], Statistics \& Information Forum.2010.8

[9] Yang,C.J., Security Investment Analysis,Shanghai, Shanghai People's Publishing House.2002.264-293

[10] Yang,C.J.,Cai,M.C, China's securities market price behavior and risk control, The national natural science fund research report[J].2000.1 